\title{
Body shape variation and colour change during growth in a protogynous fish
}

Carmelo Fruciano, Concetta Tigano, Venera Ferrito

Dipartimento di Scienze Biologiche, Geologiche e Ambientali-University of Catania, via Androne 81, 95124 Catania, Italy

7 Corresponding author

8 Carmelo Fruciano

9 Telephone +390957306023

$10 \quad$ Fax +39095327990

11 e-mail c.fruciano@unict.it

12 current address: Laboratory for Zoology and Evolutionary Biology, Department of Biology,

13 University of Konstanz, Universitätsstrasse 10, 78464 Konstanz, Germany

15 Keywords: Geometric morphometrics, Labridae, labrids, colour change, protogyny, parallel coordinates

18 Abstract Protogynous sequential hermaphroditism is very common in marine

19 fish. Despite a large number of studies on various aspects of sequential

20 hermaphroditism in fish, the relationship between body shape and colour during

21 growth in dichromatic species has not been assessed. Using geometric

22 morphometrics, the present study explores the relationship between growth, body

23 shape and colouration in Coris julis (L. 1758), a small protogynous labrid species

24 with distinct colour phases. Results show that body shape change during growth is

25 independent of change in colour phase, a result which can be explained by the

26 biology of the species and by the social control of sex change. Also, during

27 growth the body grows deeper and the head has a steeper profile. It is

28 hypothesized that a deeper body and a steeper profile might have a function in

29 agonistic interactions between terminal phase males and that the marked

30 chromatic difference between colour phases allows the lack of strict

31 interdependence of body shape and colour during growth. 


\section{Introduction}

33 Hermaphroditism is widespread in marine fish where it is present both as simultaneous and

34 sequential hermaphroditism (Shapiro 1979; Warner 1984). While many aspects of sequential

35 hermaphroditism, e.g. gonadal tissutal and morphological variation, body colour variation and size

36 at sex change, in fish have been extensively studied, to the best of the authors' knowledge the

37 relationship between body shape and colour has not been assessed in fish species in which

38 different sexual phases show different colouration. This has happened despite of the fact that the

39 size-advantage hypothesis of sex change and its variations have been extensively explored

40 (Warner 1984,1988; Muñoz and Warner 2003,2004; Warner and Muñoz 2008) and despite of the

41 fact that both body shape feature and colouration are correlated to reproductive or territorial

42 success in a few fish species (Warner and Schultz 1992; Kuwamura et al. 2000). The family

43 Labridae comprises species in which the sexes differ in colour. The first colouration, usually

44 associated to females, is often called "primary livery" while the second colouration, usually

45 associated with males, is called "secondary livery" (Tortonese 1970). Various labrid species are

46 also diandric - that is, there are individuals, called "primary males", which are males but present

47 the primary livery (Reinboth 1967; Warner and Robertson 1978). Coris julis (Linnaeus 1758) is a

48 small protogynous diandric labrid species, which is common along most of the Mediterranean Sea

49 coasts but also inhabits Eastern Atlantic coasts. Recent studies have shown that $C$. julis lacks

50 genetic structuring at the Mediterranean scale (Fruciano et al. 2011a) but nonetheless shows

51 regional morphometric variation (Fruciano et al. 2011b; Fruciano et al. in press) and that patterns

52 of morphological variation in geographic space can be different between colour phases. Coris julis

53 also shows a certain degree of variability in colour pattern. In fact, primary individuals are known

54 to vary in colour from a brown-based pattern to a reddish pattern as water depth increases and have

55 been found to be greener in Caulerpa taxifolia meadows (Michel et al. 1987; Arigoni et al. 2002).

56 The primary and secondary liveries of $C$. julis are so different that they were originally described

57 as two different species: Labrus giofredi (Risso, 1810) and C. julis (L. 1758). Behavioural

58 observations (Lejeune 1982; Bentivegna and Cirino 1984) have shown that individuals with

59 primary liveries are sedentary, while individuals with secondary liveries are territorial and engage

60 in agonistic behaviours when they meet each other, especially during the reproductive season.

61 Social factors (male/female ratio) have been shown to induce sexual inversion in the species

62 (Bentivegna and Cirino 1984). Histological aspects of sex inversion in C. julis have been described 
Fruciano C, Tigano C, Ferrito V. 2012. Body shape variation and colour change during growth in a protogynous fish.

Environmental Biology of Fishes 94(4), 615-622.

This is the accepted version of the manuscript. The final publication is available at http://link.springer.com/article/10.1007/s10641-011-9968-y

63 by Bruslé (1987) and Bentivegna et al. (1985), who also noticed a correlation between colour

64 phase and gonadic state. The variation in colouration during sex change, which creates a

65 transitional form with intermediate colouration traits called "transition livery", has been described

66 by Bentivegna and Cirino (1984) who also commented that the changes in colour marks during

67 transition do not always follow the same order. It is unclear, however, if the hormonal changes

68 which are believed to result in colour (and sex) change in this and other labrid species (Reinboth

69 1975,1988; Reinboth and Brusle-Sicard 1997; Frisch 2004; Ohta et al. 2008) at the same time also

70 cause a variation in body morphology or if the two processes are at least partially independent. In

71 fact, given that certain features of body shape have been shown to be important in territorial

72 interactions among secondary males (Warner and Schultz 1992), it could be expected that a change

73 in sex and colouration would result at the same time in a change in body shape. For this reason,

74 analysing the relationships between size, shape and colouration - as opposed to studying only one

75 trait at a time - can help understanding the relative importance of each morphological feature in

76 the biology of hermaphrodite fish species. Therefore, the aim of this study was to determine if

77 colouration and body shape changes happen simultaneously by using geometric morphometrics

78 coupled with both exploratory and hypothesis-testing statistical tools.

\section{$80 \quad$ Materials and methods}

\section{Dataset preparation}

82 For the present study, a total of 263 Coris julis specimens, sampled with fish traps, nets, fishing

83 rods and hand lines at 9 different Mediterranean sites (Fig. 1; Table 1), was used. Fish were

84 preserved in $95 \%$ ethanol and brought to the laboratory for the acquisition of morphometrical data.

85 The colour phase of each specimen was determined by visual inspection of the colour marks,

86 identifying as transitional the individuals with colour patterns intermediate between primary and

87 secondary individuals, as described in Bentivegna and Cirino (1984).

88 Pictures of the left side of each specimen were taken using an Olympus C-3030 digital camera

89 mounted on a copy stand. Each specimen was photographed two times and points were digitized

90 two times for each pictures, obtaining a total of 4 sets of coordinates per specimen (such a design 
Fruciano C, Tigano C, Ferrito V. 2012. Body shape variation and colour change during growth in a protogynous fish.

Environmental Biology of Fishes 94(4), 615-622.

This is the accepted version of the manuscript. The final publication is available at http://link.springer.com/article/10.1007/s10641-011-9968-y

91 was deemed appropriate following the results of a preliminary study on measurement error on a

92 subset of specimens). In the course of the data gathering phase, several measures have been taken

93 to minimize bias and error: the digital camera was relatively distant $(495 \mathrm{~mm})$ from the specimens

94 to reduce the effect of parallax (Mullin and Taylor 2002), fish were kept straight by running a long

95 needle of appropriate length through the right side of the body (Windsor Aguirre, pers comm) as to

96 limit dorso-ventral arching, all the steps of the analysis were performed by the same operator,

97 individuals of one population were not all photographed and digitized within the same session but

98 in different ones to avoid any bias in the way the operator performed his tasks (Windsor Aguirre,

99 pers comm); further details on methodological steps are provided by Fruciano (2009).

100 Twenty points (Fig. 2), comprising both landmarks (i.e. homologous points) and semilandmarks

101 (i.e. points which are not homologous but retain positional correspondence), were digitized using

102 the software tpsDig (Rohlf 2006). The landmark/semilandmark configurations were then subjected

103 to a generalized Procustes analysis with sliding semilandmarks (Bookstein 1997) using the

104 software tpsRelw (Rohlf 2007a), setting ten iterations and the minimization of the squared

105 Procrustes distance as sliding criterion because this criterion removes all the tangential variation

106 along outlines (Perez et al. 2006).

107 To reduce both directional and non-directional measurement error, the full dataset comprising four

108 landmark configurations for each specimen was subjected to the procedure described in Valentin et

109 al. (2008), then the resulting coordinates of each specimen (now adjusted for body arching) were

110 averaged in order to obtain a single landmark configuration for each specimen. Centroid size (the

111 square root of the summed squared distances of each landmark from the center of the form;

112 Bookstein 1989) was also computed for each of the four landmark configuration per specimen and

113 then averaged to obtain an average centroid size per specimen.

\section{Statistical analyses}

115 Body shape variation during growth was studied with two approaches: regression on a size

116 measure (centroid size) and exploratory plots of both relative warps and relative warps in size-

117 shape space (Mitteroecker et al. 2004).

118 Regression of shape variables on centroid size were performed with tpsRegr (Rohlf 2007b),

119 visualizing shape variation with a "wireframe graph" produced by the software MorphoJ

120 (Klingenberg 2011). 
Fruciano C, Tigano C, Ferrito V. 2012. Body shape variation and colour change during growth in a protogynous fish.

Environmental Biology of Fishes 94(4), 615-622.

This is the accepted version of the manuscript. The final publication is available at http://link.springer.com/article/10.1007/s10641-011-9968-y

121 Relative warps in size-shape space were computed as explained by Mitteroecker et al. (2004),

122 adding to the usual shape variables the natural logarithm of centroid size and then performing a

123 principal component analysis (PCA). Plots of individual scores on the first three PC axes were

124 finally obtained with the software STATISTICA (StatSoft, Inc.).

125 To further explore the relationships among size, shape and colour phase in more than three

126 dimensions of multivariate space, we also obtained parallel coordinate plots of relative warps.

127 Using parallel coordinates (Inselberg 1985; Wegman 1990) is an approach that allows a

128 visualization of data with more than three dimensions by avoiding the use of orthogonal axes and

129 substituting them with parallel axes. For each observation (individual) the value of a certain

130 variable is represented by a point on the corresponding vertical axis (each axis represents a

131 variable). The points for each observation on each axis are then usually linked by segments so that

132 each observation (individual) in a sample is represented by a poly-line with vertices on the axes

133 with the position of the $\mathrm{i}$-th vertice corresponding to the value of the $\mathrm{i}$-th variable. While the

134 parallel coordinates technique has been employed in various fields, especially for a visual

135 exploration of data, its use in biology has been rare (Shapley 2004) and, to the best of the authors'

136 knowledge, it has never been used with geometric morphometric data.

137 To check for possible bias in the analysis due to unequal sample sizes or to geographic variation,

138 we also carried out the above-mentioned analyses on a single population (Mallorca) and on a

139 subset of geographically close sampling sites (Augusta, Riposto, Mazara del Vallo, Pantelleria).

140 To quantify the degree of overlap between the portions of morphospace occupied by primary and

141 secondary individuals, we computed the ratio of the convex hull volume (the volume of the n-

142 dimensional minimal convex set enclosing a certain set of observation; see Cornwell et al 2006 for

143 an example in ecology) shared by both primary and secondary individuals on the total convex hull

144 volume for primary and secondary primary and secondary individuals. Convex hull computations

145 were performed on the first ten relative warps using the Quickhull algorithm (Barber et al 1996)

146 implemented in Octave (http://www.octave.org/). 


\section{Results}

149 The regression of shape on centroid size was highly significant (Wilk's Lambda 0.27; $p<0.001$ )

150 and explained $23.5 \%$ of total variance. Fig 3 depicts body shape changes associated with changes

151 in size and shows a deepening of body during growth and that the relative positions of the eye and

152 the forehead change during growth with the eye closer to the forehead in larger specimens which

153 also show a steeper head profile.

154 In size-shape space, the first relative warp (principal component) was, as expected, highly

155 correlated with the logarithm of centroid size $(r=0.99)$. The scatterplot of relative warps in size-

156 shape space (Fig 4) shows that primary and secondary specimens tend to occupy different portions

157 of the multivariate space. Therefore, given that the first principal component has a very high

158 correlation with the size measure and given that successive axes are orthogonal to the first in

159 multivariate space, it can be argued that, if in general terms primary and secondary specimens

160 occupy different portions of the size-shape space, they are different both in size and in shape.

161 However, there is also a certain degree of overlap between the groups of primary and secondary

162 specimens. It is also evident that transitional specimens do not occupy a definite and exclusive

163 portion of the multivariate space - they are scattered across areas where either primary or

164 secondary specimens are prevalent.

165 A similar situation is evident observing the parallel coordinates plot of relative warp scores

166 (Supplementary Fig. S1), which allows visualization of more than three dimensions and where

167 there is a substantial overlap of portions of morphospace occupied by primary and secondary

168 specimens (with a few primary individuals in portions of the space where secondary individuals

169 are prevalent and vice-versa). Observing the parallel coordinate plot, it is also clear that, even

170 considering ten dimensions in the multivariate space of relative warps, the transitional specimens

171 do not occupy a definite cluster. These results do not change restricting the parallel coordinates

172 plot to the quartiles of each livery - that is, considering only the main portions of morphospace

173 occupied by each colour phase - as shown in Supplementary Fig. S2.

174 Convex hull volume computations revealed that $12.37 \%$ of the morphospace of occupied by

175 primary and secondary individuals is shared between colour phases.

176 Analyses carried out on a single sampling site and on the subset of geographically close sampling

177 sites gave similar results with significant regression of shape variables on centroid size (Wilk's 
Fruciano C, Tigano C, Ferrito V. 2012. Body shape variation and colour change during growth in a protogynous fish.

Environmental Biology of Fishes 94(4), 615-622.

This is the accepted version of the manuscript. The final publication is available at http://link.springer.com/article/10.1007/s10641-011-9968-y

178 Lambda 0.13 and $\mathrm{p}=0.03$ for the Mallorca sampling site, Wilk's Lambda $0.19 ; \mathrm{p}<0.001$ for the

179 pooled Sicilian sampling sites) and plots of relative warps and relative warps in size-shape space

180 showing a certain degree of overlap between colour phases (data not shown).

181

182 Discussion

183 In all the plots of relative warps and relative warps in size-shape space it can be noticed that, while

184 in general primary and secondary specimens occupied different portions of multivariate spaces,

185 there was also a certain degree of overlap (12.37\% of convex hull volume). This means that there

186 are typical "feminine" (primary) and "masculine" traits of body shape but not all the specimens of

187 a certain livery conform to this model (that is, there are primary individuals with secondary traits

188 and vice versa). It is also remarkable that in both relative warps and relative warps in size-shape

189 space transitional individuals do not form a definite cluster. While the absence of a definite critical

190 size for colour change - evidenced in our analysis by the overlap of primary, transitional and

191 secondary specimens along the first axis in size-shape space - has already been highlighted in

192 Coris julis (Bentivegna and Cirino 1984), the overlap in body shape is a new finding. Bentivegna

193 and Cirino (1984) proposed that in C. julis there could be individuals that always retain the female

194 phase and showed that sexual inversion can be triggered by social factors (male/female ratio).

195 Social control of sex change is considered common in species with haremic social systems in

196 which dominant males control access to females (Muñoz and Warner 2004). In the light of

197 Bentivegna and Cirino’s (1984) observations, our results suggest that shape changes simply

198 happen during growth without regard to colour phase and that livery changes can happen at most

199 of growth stages without interfering with changes in body shape. So, if at a certain point during

200 growth the conditions for livery (sexual) change are present, the individual changes its colour, if

201 not it continues to grow changing its shape without changing its colouration.

202 However, given that specimens with secondary colour pattern are territorial and engage in

203 agonistic interactions with each other (Lejeune 1982; Bentivegna and Cirino 1984), and given that

204 the species is protogynous, most larger specimens are secondary while very large primary

205 specimens are rare. This is in agreement with a size-advantage hypothesis of sex change. In fact, it

206 has been noticed in other protogynous species that the females mate chiefly with larger, older 
Fruciano C, Tigano C, Ferrito V. 2012. Body shape variation and colour change during growth in a protogynous fish.

Environmental Biology of Fishes 94(4), 615-622.

This is the accepted version of the manuscript. The final publication is available at http://link.springer.com/article/10.1007/s10641-011-9968-y

207 males and this factor of strong sexual selection often leads to sexual dimorphism, with males

208 developing specialized structures and colourations for combat and display (Warner and Robertson

209 1978). A positive correlation of size with reproductive success has been noticed in Halichoeres

210 melanurus males, where it has been hypothesized that size is an important trait in male-male

211 territorial competition while male colouration is important for female mate choice (Kuwamura et

212 al. 2000).

213 Our study also highlights that larger specimens (which are usually secondary in colouration and

214 males) have a deeper body and a steeper head profile, a situation which resembles what happens in

215 other species. In fact, males of many kinds of bony fishes have a prominent nuchal hump on top of

216 the head (Barlow and Siri 1997). In particular, such a nuchal hump has been studied in neotropical

217 cichlids and various hypotheses have been tested to explain this trait (Barlow 1998). However,

218 while Barlow (1998) suggests that in Amphilophus citrinellus the presence of a nuchal hump can

219 be a means of sex recognition, this hardly applies to $C$. julis due to the striking difference in colour

220 patterns between primary and secondary specimens in this species. Here, it is hypothesized that the

221 deeper body and steeper head profile accompany the striking secondary colour pattern, enhancing

222 it (the vivid colours are probably more visible in a bigger and deeper body) for social display

223 purposes (for instance in mate choice or in agonistic relationships between secondary males). It is

224 worth noticing that in Thalassoma bifasciatum terminal males body depth is positively correlated

225 with the success in defending territories from smaller males (Warner and Schultz 1992). A survey

226 of pictures and drawings (Randall and Kuiter 1982; Gomon and Randall 1984; Randall unpubl

227 data) of other Coris species also reveals that a deeper body with growth/terminal livery is easily

228 recognizable in Coris aygula, C. ballieui, C. bulbifrons, C. cuvieri, C. debueni, C. formosa, C.

229 gaimard, C. hewetti and C. sandeyeri. Coris aygula and C. bulbifrons also develop a nuchal hump

230 similar to the one found in cichlid species. These findings suggest that the pattern described here is

231 common to other labrid species of the genus and might represent a new avenue for research on

232 sequentially hermaphroditic fish species. In fact, it is possible that the pronounced difference in

233 colour between primary and secondary specimens observed in C. julis allows the observed

234 decoupling of body shape and colour phase, leaving body shape to be a useful but not strictly

235 necessary "enhancer" of the function of colour. Alternatively, body shape might be more important

236 in species where chromatic differences between liveries are less pronounced; in these cases, colour

237 and body shape changes during growth might be more strictly linked. The relative importance of 
Fruciano C, Tigano C, Ferrito V. 2012. Body shape variation and colour change during growth in a protogynous fish.

Environmental Biology of Fishes 94(4), 615-622.

This is the accepted version of the manuscript. The final publication is available at http://link.springer.com/article/10.1007/s10641-011-9968-y

238 colouration and body shape in aggressive and/or display behaviour of secondary individuals will

239 need to be more thoroughly tested in $C$. julis and similar species.

240 Conclusions

$241 C$. julis shows a significant allometric variation in body shape which results in deeper bodies in

242 larger individuals. While on average secondary individuals possess a deeper body compared to

243 primary individuals - a common occurrence also in other species of the genus - body shape in $C$.

244 julis changes during growth without being constrained by colour phase. For this reason, it can be

245 argued that secondary individuals have, on average, a deeper body, just because they are larger and

246 that the hormonal changes which result in sex and colour change seem not to have effect on body

247 shape.

248 Finally, our study also shows that parallel coordinate plots can be a useful exploratory tool when

249 dealing with geometric morphometric data.

\section{Acknowledgements}

252 The authors would like to acknowledge the precious contribution of F. James Rohlf who provided

253 many useful suggestions at multiple stages. Enrico Arneri, Ferdinando Boero, G. Andrea de Lucia,

254 Paolo Domenici, Maria Ghelia, Paolo Guidetti, Miquel Palmer, Sergio Ragonese, Alfonso Toscano

255 and Nedo Vrgoc kindly helped in obtaining specimens used in the analysis.

\section{References}

258 Arigoni S, Francour P, Harmelin-Vivien M, Zaninetti L (2002) Adaptive colouration of

Mediterranean labrid fishes to the new habitat provided by the introduced tropical alga

Barber CB, Dobkin DP, Huhdanpaa HT (1996) The Quickhull algorithm for convex hulls. ACM T

263 Barlow GW (1998) Sexual-selection models for exaggerated traits are useful but constraining. Am 
Fruciano C, Tigano C, Ferrito V. 2012. Body shape variation and colour change during growth in a protogynous fish.

Environmental Biology of Fishes 94(4), 615-622.

This is the accepted version of the manuscript. The final publication is available at http://link.springer.com/article/10.1007/s10641-011-9968-y

265 Barlow GW, Siri P (1997) Does sexual selection account for the conspicuous head dimorphism in the Midas cichlid? Anim Behav 52:573-584.

267 Bentivegna F, Cirino P (1984) Sexual inversion in Coris julis L. 1758. Cybium 8(2):51-61.

268 Bentivegna F, Cirino P, Rasotto MB (1985) Further investigations into sex reversal of Coris julis

269 L. (Pisces, Labridae). Boll Zool 52:355-358.

270 Bookstein FL (1989) "Size and shape”: a comment on semantics. Syst Zool 38:173-180.

271 Bookstein FL (1997) Landmark methods for forms without landmarks: localizing group

272 differences in outline shape. Med Image Anal 1:225-243.

273 Bruslé S (1987). Sex-inversion of the hermaphroditic, protogynous teleost Coris julis L.

274 (Labridae). J Fish Biol 30:605-616.

275 Cornwell WK, Schwilk DW, Ackerly DD (2006). A trait-based test for habitat filtering: convex 276 hull volume. Ecology 87(6):1465-1471.

277 Frisch A (2004) Sex-change and gonadal steroids in sequentially-hermaphroditic teleost fish. Rev $278 \quad$ Fish Biol Fisher 14:481-499.

279 Fruciano C (2009) Pattern di variazione morfologica e molecolare in Coris julis (L. 1758)

280 (Teleostei, Labridae). Doctoral thesis, University of Catania.

281 Fruciano C, Hanel R, Debes PV, Tigano C, Ferrito V (2011a) Atlantic-Mediterranean and withinMediterranean molecular variation in Coris julis (L. 1758) (Teleostei, Labridae). Mar

284 Fruciano C, Tigano C, Ferrito V (2011b) Geographic morphological variation within and between colour phases in Coris julis (L. 1758), a protogynous marine fish. Biol J Linn Soc

287 Fruciano C, Ferrito V, Tigano C in press. Traditional and geometric morphometrics detect 288 morphological variation of lower pharyngeal jaw in Coris julis (Teleostei, Labridae). Ital J Zool

290 Gomon MF, Randall JE (1984) Labridae. In: Fischer W and Bianchi G (eds) FAO species identification sheets for fishery purposes. Western Indian Ocean fishing area 51. Vol. 2.

292 Inselberg A (1985) The plane with parallel coordinates. Visual Comput 1:69-91.

293 Klingenberg CP (2011) MorphoJ: an integrated software package for geometric morphometrics.

$294 \quad$ Mol Ecol Res 11:353-357. 
Fruciano C, Tigano C, Ferrito V. 2012. Body shape variation and colour change during growth in a protogynous fish.

Environmental Biology of Fishes 94(4), 615-622.

This is the accepted version of the manuscript. The final publication is available at http://link.springer.com/article/10.1007/s10641-011-9968-y

295 Kuwamura T, Karino K, Nakashima Y (2000) Male morphological characteristics and mating success in a protogynous coral reef fish, Halichoeres melanurus. J Ethol 18:17-23.

297 Lejeune P (1982) A propos de quelques Poissons de la Mediterraneé. Revue Francaise

298 d'Aquariologie 9(1):27-32.

299 Michel C, Lejeune P, Voss J (1987) Biologie et comportement des Labridés européens (Labres,

300 Crénilabres, Rouquiers, Vieilles et Girelles). Revue française d'Aquariologie 14:1-180.

301 Mitteroecker P, Gunz P, Bernhard M, Schaefer K, Bookstein FL (2004) Comparison of cranial

302 ontogenetic trajectories among great apes and humans. J Hum Evol 46:679-698.

303 Mullin SK, Taylor PJ (2002) The effects of parallax on geometric morphometric data. Comput

$304 \quad$ Biol Med 32: 455-464.

305 Muñoz RC, Warner RR (2003) A new version of the size-advantage hypothesis for sex change:

306 incorporating sperm competition and size-fecundity skew. Am Nat 161(5):749-761.

307 Muñoz RC, Warner RR (2004) Testing a new version of the size-advantage hypothesis for sex

308 change: sperm competition and size-skew effects in the bucktooth parrotfish, Sparisoma

309 radians. Behav Ecol 15(1):129-136.

310 Ohta K, Hirano M, Mine T, Mizutani H, Yamaguchi A, Matsuyama M (2008) Body color change

311 and serum steroid hormone levels throughout the process of sex change in the adult

$312 \quad$ wrasse, Pseudolabrus sieboldi. Mar Biol 153(5):843-852.

313 Perez IS, Bernal V, Gonzalez PN (2006) Differences between sliding semilandmark methods in

314 geometric morphometrics, with an application to human craniofacial and dental variation.

$315 \quad$ J Anat 208: 769-784.

316 Randall JE, Kuiter RH (1982) Three new Labrid fishes of the genus Coris from the Western

317 Pacific. Pac Sci 36(2):159-173.

318 Reinboth R (1967) Biandric Teleost species. Gen Comp Endocr, Abstracts, 9: no. 146.

319 Reinboth R (1975) Spontaneous and hormone-induced sex-inversion in wrasses (Labridae).

320 Pubblicazioni della Stazione Zoologica di Napoli 39(suppl):550-573

321 Reinboth R (1988) Physiological problems of teleost ambisexuality. Environ Biol Fish 22(4):249-

$322 \quad 259$.

323 Reinboth R, Brusle-Sicard S (1997) Histological and ultrastructural studies on the effects of hCG

324 on sex inversion in the protogynous teleost Coris julis. J Fish Biol 51:738-749. 
Fruciano C, Tigano C, Ferrito V. 2012. Body shape variation and colour change during growth in a protogynous fish.

Environmental Biology of Fishes 94(4), 615-622.

This is the accepted version of the manuscript. The final publication is available at $h$ ttp://link.springer.com/article/10.1007/s10641-011-9968-y

325 Rohlf FJ (2006) tpsDig, digitize landmarks and outlines, version 2.10. Department of Ecology and 326 Evolution, State University of New York at Stony Brook.

327 Rohlf FJ (2007)a. tpsRelw, relative warps analysis, version 1.45. Department of Ecology and 328 Evolution, State University of New York at Stony Brook.

329 Rohlf FJ (2007)b. tpsRegr, shape regression, version 1.33. Department of Ecology and Evolution, 330 State University of New York at Stony Brook.

331 Shapiro DY (1979) Social behavior, group structure, and the control of sex reversal in

Shapley RL (2004) Assessing parallel coordinates visualizations for prestatistical exploration of

337 Tortonese E (1970) Fauna d'Italia - Osteichthyes - Pesci Ossei. Ed. Calderini Bologna.

338 Valentin AE, Penin X, Chanut J-P, Sévigny J-M, Rohlf FJ (2008) Arching effect on fish body shape in geometric morphometric studies. J Fish Biol 73:623-638.

340 Warner RR (1984) Mating behavior and hermaphroditism in coral reef fishes. Am Sci 72(2):128341136

342 Warner RR (1988) Sex change in fishes: hypotheses, evidence, and objections. Env Biol Fish 22(2):81-90.

344 Warner RR, Muñoz RC (2008) Needed: a dynamic approach to understand sex change. Anim Behav 75:e11-e14.

346 Warner RR, Robertson DR (1978) Sexual patterns in the labroid fishes of the western Caribbean, I: the Wrasses (Labridae). Smithson Contrib Zool 254:1-27.

348 Warner RR, Schultz ET (1992) Sexual selection and male characteristics in the bluehead wrasse, Thalassoma bifasciatum: mating site acquisition, mating site defense, and female choice. Evolution 46(5):1421-1442.

351 Wegman EJ (1990) Hyperdimensional data analysis using parallel coordinates. J Am Stat Assoc 85:664-675. 


\section{Figure captions}

355 Fig. 1 Geographic locations for the samples used in the study. AU=Augusta, SR, Italy; LE=Porto

356 Cesareo, LE, Italy; ML=Badia de Palma, Mallorca, Spain; MA=Mazara del Vallo, TP, Italy;

357 NA=Capo Posillipo, Naples, Italy; OR=Oristano, Italy; PN=Pantelleria, Italy; RI=Riposto, CT,

358 Italy; SP=Split, Croatia

360 Fig. 2 Position of the points used for the analysis of body shape. Filled circles represent

361 landmarks, open circles semilandmarks

363 Fig. 3 Change in shape associated with change in size represented with a "wireframe graph"

364 produced by the software MorphoJ. The dashed grey line represents a reference shape, the black

365 solid line represents the change in shape relative to the reference as the body size increases

367 Fig. 4 Three-dimensional scatterplot of the first three relative warps (RW) in size-shape space;

368 the scale of the axes has been distorted deliberately to visualize the patterns on RW2 and RW3.

369 The plot shows a considerable overlap of primary and secondary individuals, as well as the lack of

370 a definite region for transitional specimens

372 Supplementary Fig. S1 Parallel coordinate plot of the first ten relative warps for all the studied

373 specimens. Yellow=primary, blue=transition, pink=secondary. The plot shows a considerable

374 overlap of the morphospace portions occupied by each colour phase

376 Supplementary Fig. S2 Parallel coordinate plot of the first ten relative warps. For each colour

377 phase only the quartiles are shown to highlight the degree of overlap among groups.

378 Yellow=primary, blue=transition, pink=secondary. The plot shows that the overlap in

379 morphospace occupation of primary, transitional and secondary individuals is not caused by a few

380 outliers but it is evident even considering only the quartiles of the relative warps of each colour

381 phase 
Table 1 Sampling data for each population used in the study

\begin{tabular}{|c|c|c|c|c|c|c|c|}
\hline \multirow{2}{*}{ Sample } & \multirow{2}{*}{ Sampling time } & \multirow{2}{*}{ Environment } & \multirow{2}{*}{ Coordinates } & \multicolumn{3}{|c|}{ Livery } & \multirow{2}{*}{ Total } \\
\hline & & & & Primary & Transition & Secondary & \\
\hline Split (SP) & March 2007 & $\begin{array}{l}\text { Posidonia oceanica } \\
\text { beds; a few meters } \\
\text { of depth }\end{array}$ & $\begin{array}{l}43^{\circ} 28^{\prime} \mathrm{N} \\
16^{\circ} 24^{\prime} \mathrm{E}\end{array}$ & 7 & 9 & 10 & 26 \\
\hline $\begin{array}{l}\text { Naples } \\
\text { (NA) }\end{array}$ & February 2007 & $\begin{array}{l}\text { Gravel bottom; 10- } \\
12 \text { meters of depth }\end{array}$ & $\begin{array}{l}40^{\circ} 46^{\prime} \mathrm{N} \\
14^{\circ} 12^{\prime} \mathrm{E}\end{array}$ & 4 & 21 & 8 & 33 \\
\hline Lecce (LE) & $\begin{array}{l}\text { May } 2007 \text { and } \\
\text { May } 2009\end{array}$ & $\begin{array}{c}\text { Patches of rocky } \\
\text { bottom and } \\
\text { Posidonia oceanica } \\
\text { beds; } 8-20 \text { meters of } \\
\text { depth }\end{array}$ & $\begin{array}{l}40^{\circ} 14^{\prime} \mathrm{N} \\
17^{\circ} 52^{\prime} \mathrm{E}\end{array}$ & 3 & 1 & 29 & 33 \\
\hline $\begin{array}{l}\text { Oristano } \\
\text { (OR) }\end{array}$ & April 2007 & $\begin{array}{l}\text { Rocky bottom with } \\
\text { photophilic algae; } \\
\text { Posidonia oceanica } \\
\text { beds; 5-6 meters of } \\
\text { depth }\end{array}$ & $\begin{array}{c}39^{\circ} 48^{\prime} \mathrm{N} \\
8^{\circ} 31^{\prime} \mathrm{E}\end{array}$ & 24 & 4 & 2 & 30 \\
\hline $\begin{array}{l}\text { Mallorca } \\
\text { (ML) }\end{array}$ & June 2007 & $\begin{array}{l}\text { Rocky bottom with } \\
\text { photophilic algae; 9- } \\
17 \text { meters of depth }\end{array}$ & $\begin{array}{c}39^{\circ} 31^{\prime} \mathrm{N} \\
2^{\circ} 39^{\prime} \mathrm{E}\end{array}$ & 21 & 2 & 19 & 42 \\
\hline $\begin{array}{l}\text { Riposto } \\
\text { (RI) }\end{array}$ & $\begin{array}{c}\text { January 2007; } \\
\text { March 2007; } \\
\text { April } 2008\end{array}$ & $\begin{array}{c}\text { Patches of rocky and } \\
\text { sandy bottom; } 4-8 \\
\text { meters of depth }\end{array}$ & $\begin{array}{l}37^{\circ} 43^{\prime} \mathrm{N} \\
15^{\circ} 13^{\prime} \mathrm{E}\end{array}$ & 26 & - & 2 & 28 \\
\hline $\begin{array}{l}\text { Mazara del } \\
\text { Vallo (MA) }\end{array}$ & June 2007 & $\begin{array}{l}\text { Posidonia oceanica } \\
\text { beds; } 3-5 \text { meters of } \\
\text { depth }\end{array}$ & $\begin{array}{l}37^{\circ} 38^{\prime} \mathrm{N} \\
12^{\circ} 35^{\prime} \mathrm{E}\end{array}$ & 14 & 2 & 19 & 35 \\
\hline $\begin{array}{l}\text { Augusta } \\
\text { (AU) }\end{array}$ & $\begin{array}{l}\text { May } 2008 \text { and } \\
\text { June } 2008\end{array}$ & $\begin{array}{l}\text { Rocky bottom with } \\
\text { few photophilic } \\
\text { algae; } 4-10 \text { meters of } \\
\text { depth }\end{array}$ & $\begin{array}{l}37^{\circ} 11^{\prime} \mathrm{N} \\
15^{\circ} 14^{\prime} \mathrm{E}\end{array}$ & 6 & - & 17 & 23 \\
\hline $\begin{array}{l}\text { Pantelleria } \\
\quad(\mathrm{PN})\end{array}$ & October 2008 & $\begin{array}{c}\text { Rocks with } \\
\text { Posidonia oceanica } \\
\text { patches close to a } \\
\text { sandy area with } \\
\text { Posidonia; } 5-15 \\
\text { meters of depth }\end{array}$ & $\begin{array}{l}36^{\circ} 50^{\prime} \mathrm{N} \\
11^{\circ} 59^{\prime} \mathrm{E}\end{array}$ & 1 & 1 & 11 & 13 \\
\hline Total & & & & 106 & 40 & 117 & 263 \\
\hline
\end{tabular}


Fig. 1

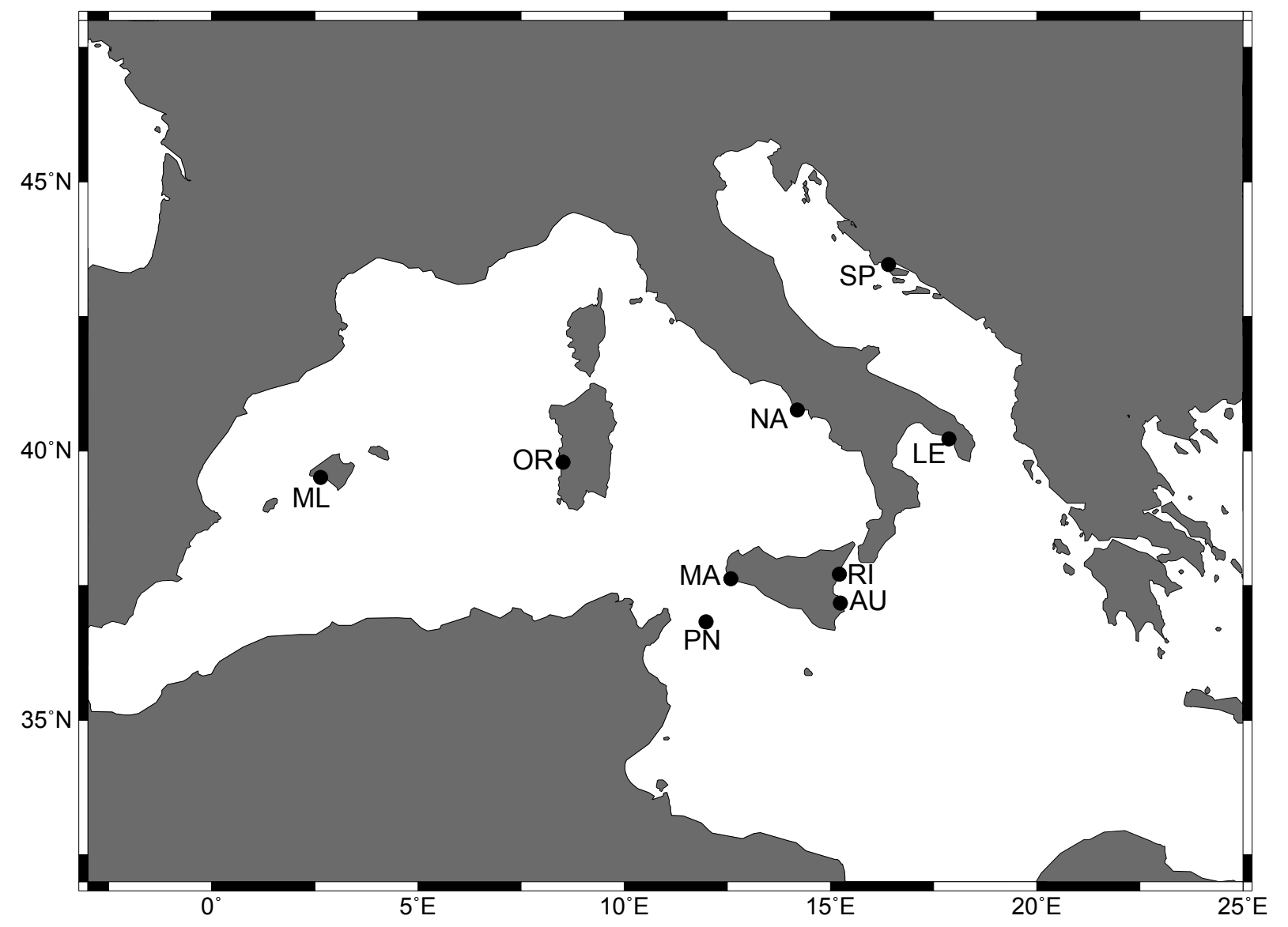




\section{Fig. 2}

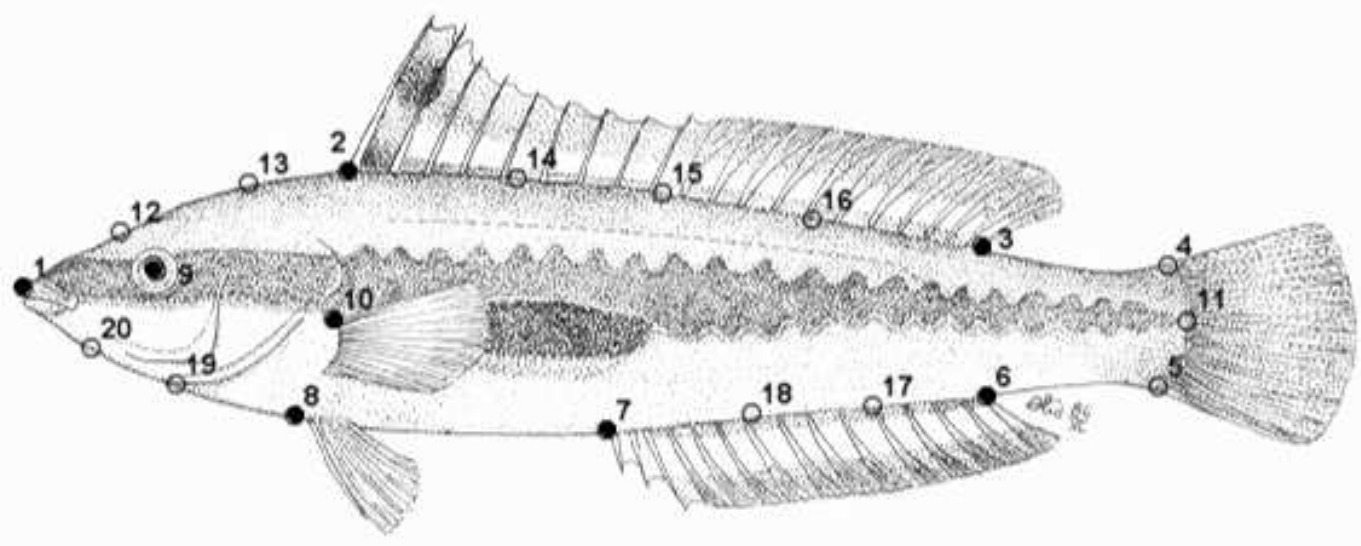


Fig. 3

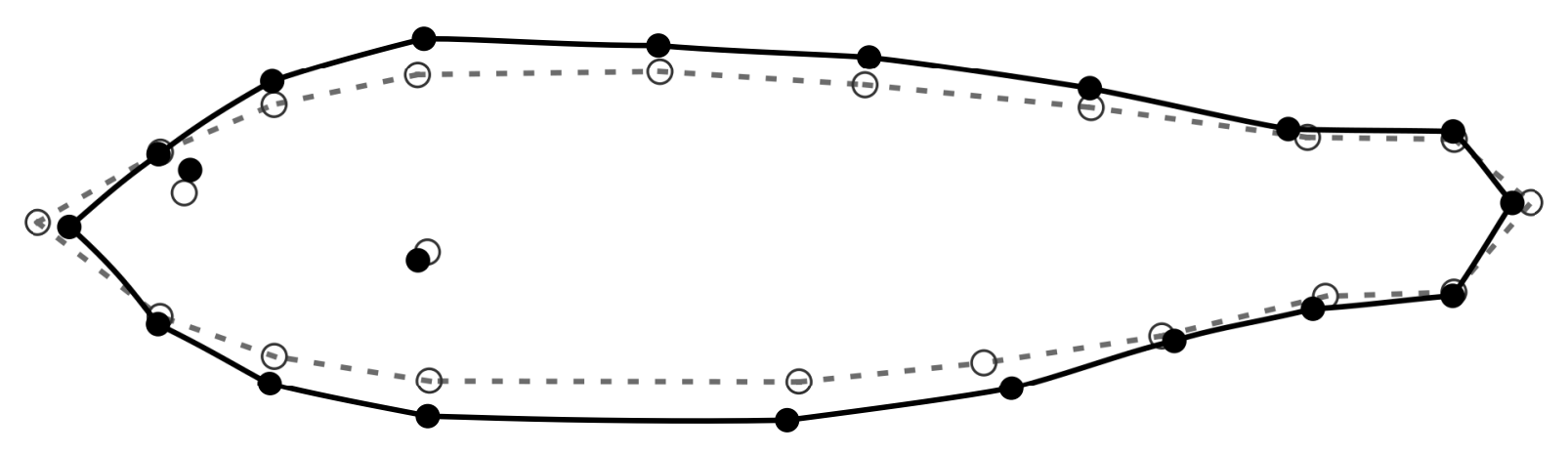




\section{Fig. 4}

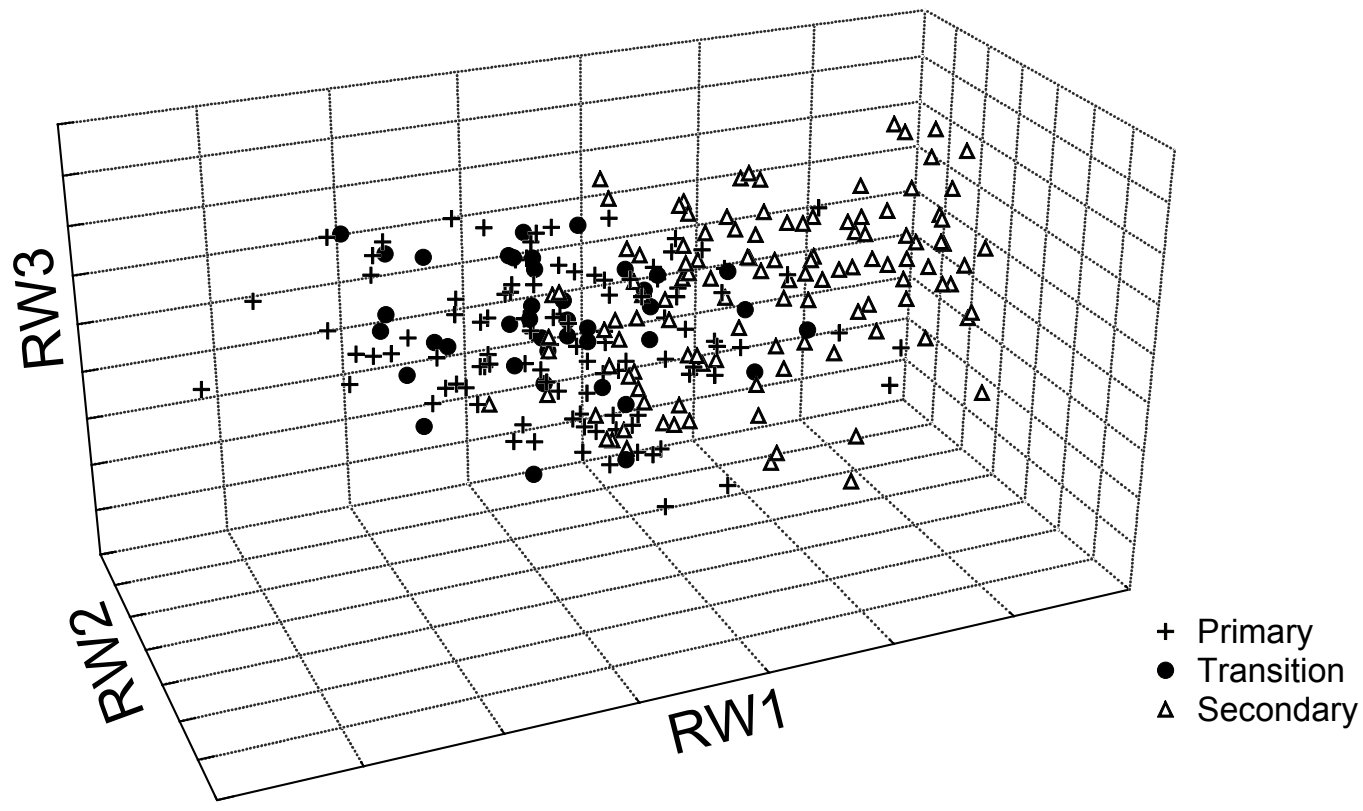


Fig. S1




Fig. S2

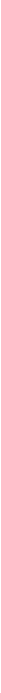

$-0.01$

$-0.015$

$-0.021$

2

3

4

5 Relative warp

8

9

10 